\title{
Modelling Nanoparticles Parameters for Antimicrobial Activity
}

\author{
L. C. Razanamahandry, A. K. H. Bashir, K. Kaviyarasu, \\ Lukhanyo Mekuto, S. K. O. Ntwampe, and M. Maaza
}

\begin{abstract}
The current study reveals the antimicrobial activity of various nanoparticles (NPs) against numerous microorganisms through statistical models that define suitable parameters to improve the antimicrobial efficacy of NPs. The antimicrobial data on NPs were collected from previously published studies, focusing on parameters such as the NPs type and size (nm), microbial strains and their initial density
\end{abstract}

L. C. Razanamahandry ( $\square)$

UNESCO-UNISA Africa Chair in Nanoscience's/Nanotechnology Laboratories (U2AC2N),

College of Graduate Studies, University of South Africa (UNISA), Pretoria, South Africa

Nanosciences African network (NANOAFNET), Materials Research Department (MRD), iThemba LABS-National Research Foundation (NRF),

Somerset West, Western Cape Province, South Africa

Bioresource Engineering Research Group (BioERG), Faculty of Applied Science, Cape Peninsula University of Technology, Cape Town, South Africa

e-mail: clrazanamahandry@tlabs.ac.za

A. K. H. Bashir · K. Kaviyarasu · M. Maaza

UNESCO-UNISA Africa Chair in Nanoscience's/Nanotechnology Laboratories (U2AC2N), College of Graduate Studies, University of South Africa (UNISA), Pretoria, South Africa

Nanosciences African network (NANOAFNET), Materials Research Department (MRD), iThemba LABS-National Research Foundation (NRF),

Somerset West, Western Cape Province, South Africa

L. Mekuto

Department of Chemical Engineering, University of Johannesburg,

Johannesburg, South Africa

S. K. O. Ntwampe

Bioresource Engineering Research Group (BioERG), Faculty of Applied Science, Cape

Peninsula University of Technology, Cape Town, South Africa

School of Chemical and Minerals Engineering, North-West University,

Potchefstroom, South Africa

(C) Springer Nature Singapore Pte Ltd. 2020

D. B. Siddhardha et al. (eds.), Model Organisms to Study Biological Activities

and Toxicity of Nanoparticles, https://doi.org/10.1007/978-981-15-1702-0_5 
(O.D.600nm), inhibition zone (IZ) size (mm), contact time (h), well and disc diffusion size $(\mathrm{mm})$ and minimum inhibitory concentration $(\mathrm{MIC})(\mu \mathrm{g} / \mathrm{mL})$. A correlation between these parameters was modelled by using a multiple correspondence analysis (MCA) and a principal component analysis (PCA) for qualitative and quantitative analysis, respectively. Results showed a significant positive correlation between the IZ size and the following parameters: MIC, well size and disc diffusion size with a Pearson ratio of $95.98 \%, 93.99 \%$ and $94.82 \%(\alpha=0.5)$, respectively. Antimicrobial efficacy by $\mathrm{Ag}, \mathrm{SiO}_{2}$ and $\mathrm{ZnO}$ NPs with a significant IZ for various gram positive bacterial strains was demonstrated. In addition, gram negative bacteria and fungi were deactivated by $\mathrm{La}-\mathrm{ZnO}$ and AgNPs. Antimicrobial tests with NPs could be improved by varying the NPs concentration for improved efficacy. The NPs type should also be chosen as a function of the target bacteria characteristics, i.e. gram staining, for higher efficacy.

\section{Keywords}

Antimicrobial activity - Multiple correspondence analysis - Nanoparticles · Principal component analysis $\cdot$ Statistical modelling

\subsection{Introduction}

The increase in anthropogenic activities such as industrialisation has serious impacts on the environment and its natural resources (Mao et al. 2019). Natural resources are the primary receptors of anthropogenic activity. Water and soil are the most affected resources by these activities and their quality and pristine nature deteriorates and subsequently results in adverse impact on human health (Razanamahandry et al. 2017). For instance, pathogenic microorganisms easily grow in the modified ecosystems with degraded natural resources (Mekuto et al. 2018). Thus, the remediation of these resources using various technologies is advisable. Bioremediation and phytoremediation are among the most applied technologies (Razanamahandry et al. 2016), as they are classified as environmentally benign.

Recently, nanosciences and nanotechnology have been developed to restore the pristine condition of the polluted environment with an aim to minimise the human health challenges (Wang 2012; Webster and Seil 2012). As an example, photocatalytic methods using nanomaterials in numerous studies demonstrated the removal of several pollutants affecting water and soil resources. Rhodamine B, methyl orange and methylene blue were removed by using $\mathrm{HAp}^{-\mathrm{TiO}_{2}}$ nanocomposites (Kaviyarasu et al. 2017b), $\mathrm{ZnO}$ nanoparticles (NPs) (Siripireddy and Mandal 2017), and $\mathrm{SnO}_{2}$ including CuO-NPs (Diallo et al. 2016; Mbu et al. 2018), respectively. In addition, Nwanya et al. (2019) have also reported the effectiveness of CuO-NPs to remediate industrial textile effluents. In terms of human health, growth of pathogenic microorganisms was inhibited by different types of nanomaterials. Bacillus cereus, Pseudomonas aeruginosa, Escherichia coli and Staphylococcus aureus are among some pathogenic microorganisms responsible for various human diseases such as diarrhoea, meningitis, 
septicaemia and many other infections (Makvana and Krilov 2015; Tong et al. 2015). Several nanoparticles were reported as effective against these microorganisms' proliferation. Ahmad et al. (2018) have conducted research on the inhibition of the growth of Escherichia coli using ZnO NPs; albeit, a small inhibition zone (13 mm) was obtained. Although, the same microorganism was tested by Karthik et al. (2017) using the same nanoparticle type and the results showed that the obtained inhibition zone was large $(30 \mathrm{~mm})$. Besides, several authors have shown the effectiveness of the following NPs; $\mathrm{Co}(\mathrm{Vox}), \mathrm{Cu}, \mathrm{Fe}_{3} \mathrm{O}_{4}, \mathrm{Ag}$ and $\mathrm{CdO}$ to inhibit the growth of E. coli, B. subtilis (Yoon et al. 2007), S. epidermidis, Vibrio cholerae (Morones et al. 2005) and P. fluorescens (Jiang et al. 2009), respectively. These research studies were conducted under different conditions. Webster and Seil (2012) has reported that bacteria species, gram straining and minimum inhibitory concentrations (MIC) are among the main parameters that should be considered for nanoparticles' antimicrobial applications. Besides, antimicrobial effectiveness of NPs could be evaluated by a well or disc diffusion assay (Valgas et al. 2007). In addition, the average size, the initial optical density of the pathogen and the contact time could influence the effectiveness of the NPs for antimicrobial activity. Nevertheless, there is a lack of studies conducted to modelling these interlinked complex parameters to assess key variable parameter variation and the role they play for inhibition effectiveness against pathogenic microorganism proliferation. These variables are complex and must be explored as combinatorial factors using mathematical and statistical modelling. Available statistical tools could therefore be used to model the identified parameters, which must be considered to obtain the highest antimicrobial effectiveness of different nanoparticles.

As such, qualitative and quantitative input variables for various research studies were resolved by using statistical tools, i.e. multiple correspondence analysis (MCA) and principal component analysis (PCA). Dungey et al. (2018) highlighted the application of MCA to modelling qualitative variables into relational moieties of significance. Moreover, PCA can be applied to reduce quantitative variables in order to optimise and to only consider variables that are highly beneficial to human health (Yacoub et al. 2013). Various applications were conducted by using MCA and PCA analyses in hydrological studies (Van Stan et al. 2016) and in human health survey (Ayele et al. 2015). The lack of statistical modelling application was perceived as a limitation for nanomaterials application in antimicrobial efficacy studies. Therefore, the aim of this research was to find nanomaterials suitable for the elimination of pathogenic microorganisms and to identify the suitable parameters which should be considered for high antimicrobial efficacy in future applications.

\subsection{Materials and Methods}

\subsubsection{Input Parameters}

Recent data $(n=123)$ on the antimicrobial efficacy of nanoparticles was sourced from previously published studies (Tables 5.1 and 5.2). Parameters, which are related to the antimicrobial application of different nanoparticle types, via surface 
Table 5.1 Qualitative input data for MCA analysis

\begin{tabular}{|c|c|c|c|}
\hline \multirow[b]{2}{*}{ NPs } & \multicolumn{2}{|c|}{ Gram staining of bacteria } & \multirow[b]{2}{*}{ Fungi } \\
\hline & Negative & Positive & \\
\hline $\mathrm{ZnO}$ & $1^{\mathrm{a}, \mathrm{c}, \mathrm{m}}$ & $1^{\mathrm{b}, \mathrm{n}}$ & $1^{\mathrm{d}}$ \\
\hline $\mathrm{Cu} 28-\mathrm{Fe} 72$ & $1^{\mathrm{a}, \mathrm{c},}$ & $1^{\mathrm{b}, \mathrm{e}}$ & 0 \\
\hline $\mathrm{Ta}_{2} \mathrm{O}_{5}$ & $1^{\mathrm{a},}$ & 0 & 0 \\
\hline $\mathrm{Ag}$ & $1^{\mathrm{a}, \mathrm{c}, \mathrm{j}, \mathrm{k}, \mathrm{l}, \mathrm{I}}$ & $1^{\mathrm{b}, \mathrm{f}-\mathrm{i}}$ & $1^{\mathrm{d},}$ \\
\hline $\mathrm{La}-\mathrm{ZnO}$ & $1^{\mathrm{j}, \mathrm{o}}$ & 0 & 0 \\
\hline $\mathrm{Co}($ Vox $)$ & $1^{\mathrm{a}, \mathrm{k}}$ & $1^{\mathrm{b}, \mathrm{e}}$ & 0 \\
\hline $\mathrm{ZnO} / \mathrm{TiO}_{2}$ & $1^{\mathrm{a}, \mathrm{q}}$ & $1^{\mathrm{b}, \mathrm{p}}$ & 0 \\
\hline $\mathrm{CeO}_{2}$ & $1^{\mathrm{a}, \mathrm{m}}$ & $1^{\mathrm{b}, \mathrm{n}}$ & 0 \\
\hline$\beta-\mathrm{CoMoO}_{4}-\mathrm{Co}_{3} \mathrm{O}_{4}$ & $1^{\mathrm{a}, \mathrm{c}}$ & $1^{\mathrm{b}}$ & 0 \\
\hline $\mathrm{CeO}_{2} / \mathrm{CdO}$ & $1^{\mathrm{c}}$ & 0 & 0 \\
\hline $\mathrm{HAp}-\mathrm{TiO}_{2}(8 \mathrm{dip})$ & $1^{\mathrm{a}}$ & $1^{\mathrm{r}}$ & 0 \\
\hline $\mathrm{Cu}$ & $1^{\mathrm{a}}$ & $1^{\mathrm{h}}$ & 0 \\
\hline $\mathrm{Fe}_{3} \mathrm{O}_{4}$ & 0 & $1^{\mathrm{b}, \mathrm{s}}$ & 0 \\
\hline $\mathrm{Al}_{2} \mathrm{O}_{3}$ & $1, \mathrm{a}, \mathrm{t}$ & $1^{\mathrm{h}}$ & 0 \\
\hline $\mathrm{TiO}_{2}$ & $1^{\mathrm{a}}$ & 0 & 0 \\
\hline $\mathrm{SiO}_{2}$ & $1 \mathrm{a}, \mathrm{t}$ & $1^{\mathrm{b}}$ & 0 \\
\hline $\mathrm{CuO}$ & $1^{\mathrm{a}, \mathrm{c}}$ & $1^{\mathrm{b}, \mathrm{y}}$ & 0 \\
\hline
\end{tabular}

Microorganisms (references). a: E. coli (Ahmad et al. 2018; Jiang et al. 2009; Karthik et al. 2017; Kaviya et al. 2011; Kaviyarasu et al. 2017a, b, c; Kennedy et al. 2017; Kim et al. 2007; Maria Magdalane et al. 2018; Meidanchi and Jafari 2019; Mobeen Amanulla et al. 2018; Morones et al. 2005; Nair et al. 2009; Nwanya et al. 2019; Padmavathy and Vijayaraghavan 2008; Pal et al. 2007; Simo et al. 2018; Simon-Deckers et al. 2009; Sondi and Salopek-Sondi 2004; Webster and Seil 2012; Yoon et al. 2007; Zhang et al. 2019). b: S. aureus (Ahmad et al. 2018; Jiang et al. 2009; Jones et al. 2008; Karthik et al. 2017; Kaviya et al. 2011; Kaviyarasu et al. 2017a, b, c; Kennedy et al. 2017; Kim et al. 2007; Maria Magdalane et al. 2018; McCarthy et al. 1992; Mobeen Amanulla et al. 2018; Nair et al. 2009; Nwanya et al. 2019; Reddy et al. 2007; Salomoni et al. 2015; Simo et al. 2018; Tran et al. 2010; Webster and Seil 2012; Zhang et al. 2019). c: P. aeruginosa (Bakina et al. 2019; Kaviya et al. 2011; Kennedy et al. 2017; Maria Magdalane et al. 2017; McCarthy et al. 1992; Mobeen Amanulla et al. 2018; Morones et al. 2005; Nwanya et al. 2019; Webster and Seil 2012). d: Candida albicans (McCarthy et al. 1992; Webster and Seil 2012; Zhang et al. 2019). e: MRSA ATCC 43300 (Bakina et al. 2019; Simo et al. 2018). f: B. cereus (Kennedy et al. 2017). g: Micrococcus luteus (Kennedy et al. 2017). h: B. subtilis (Jiang et al. 2009; Kennedy et al. 2017; Webster and Seil 2012; Yoon et al. 2007). i: Enterococcus sp (Kennedy et al. 2017). j: Salmonella typhi (Kennedy et al. 2017; Manikandan et al. 2017; Morones et al. 2005; Webster and Seil 2012). k: Klebsiella pneumoniae (Kennedy et al. 2017; Simo et al. 2018). 1: V. cholerae (Morones et al. 2005; Webster and Seil 2012). m: E. hermannii (Kaviyarasu et al. 2017a, b, c; Maria Magdalane et al. 2018). n: S. pneumoniae (Kaviyarasu et al. 2017a, b, c; Maria Magdalane et al. 2018). o: Proteus mirabilis (Manikandan et al. 2017). p: Streptococcus mutans (Kaviyarasu et al. 2017a). q: Salmonella sps (Kaviyarasu et al. 2017a). r: Bacillus spp (Kaviyarasu et al. 2017b). s: S. epidermidis $^{6,17}$. t: P. fluorescens (Jiang et al. 2009; Webster and Seil 2012)y: Bacillus licheniformis (Nwanya et al. 2019)

1 data available, $O$ data not available 


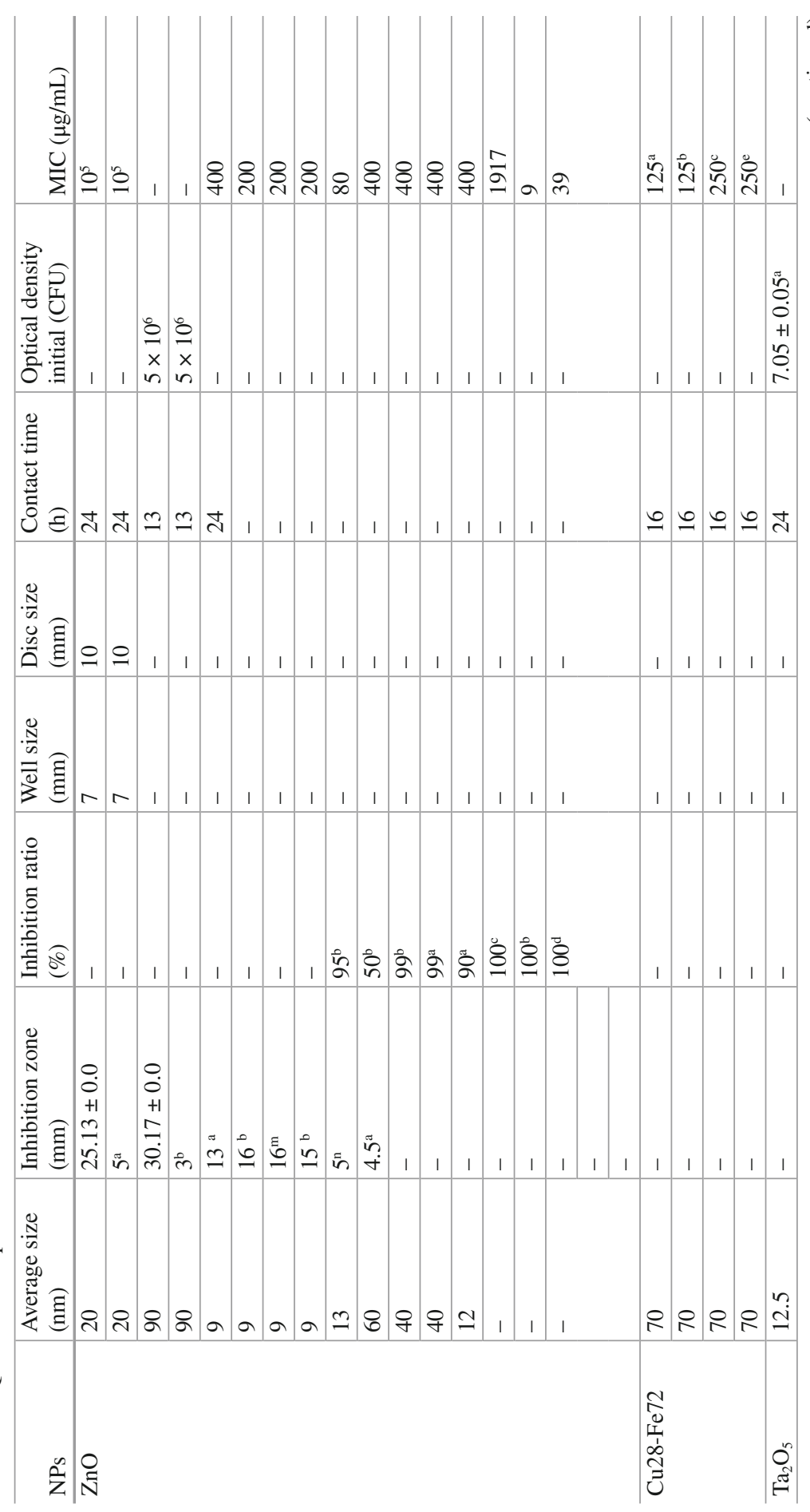




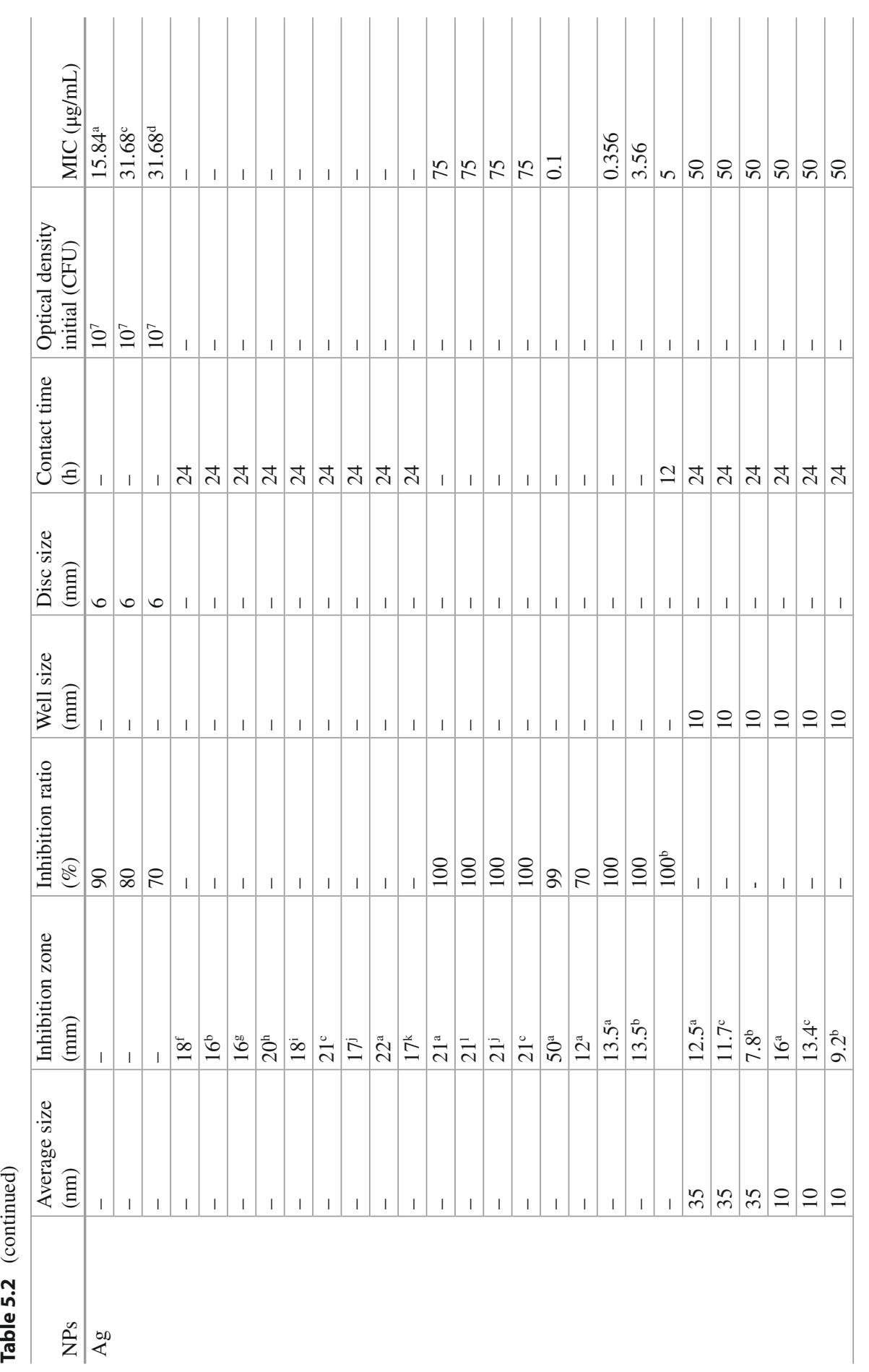




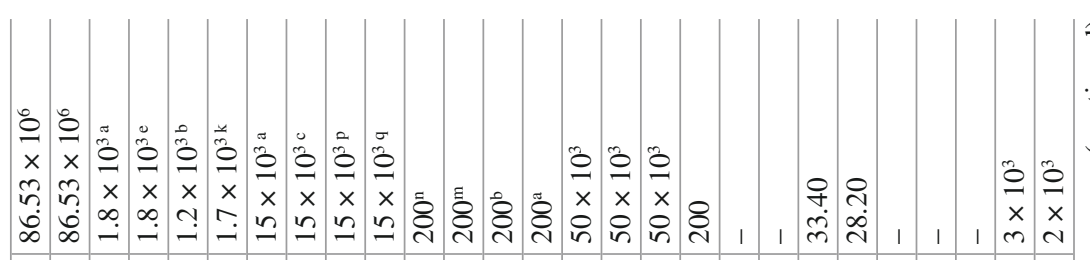

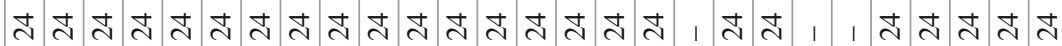

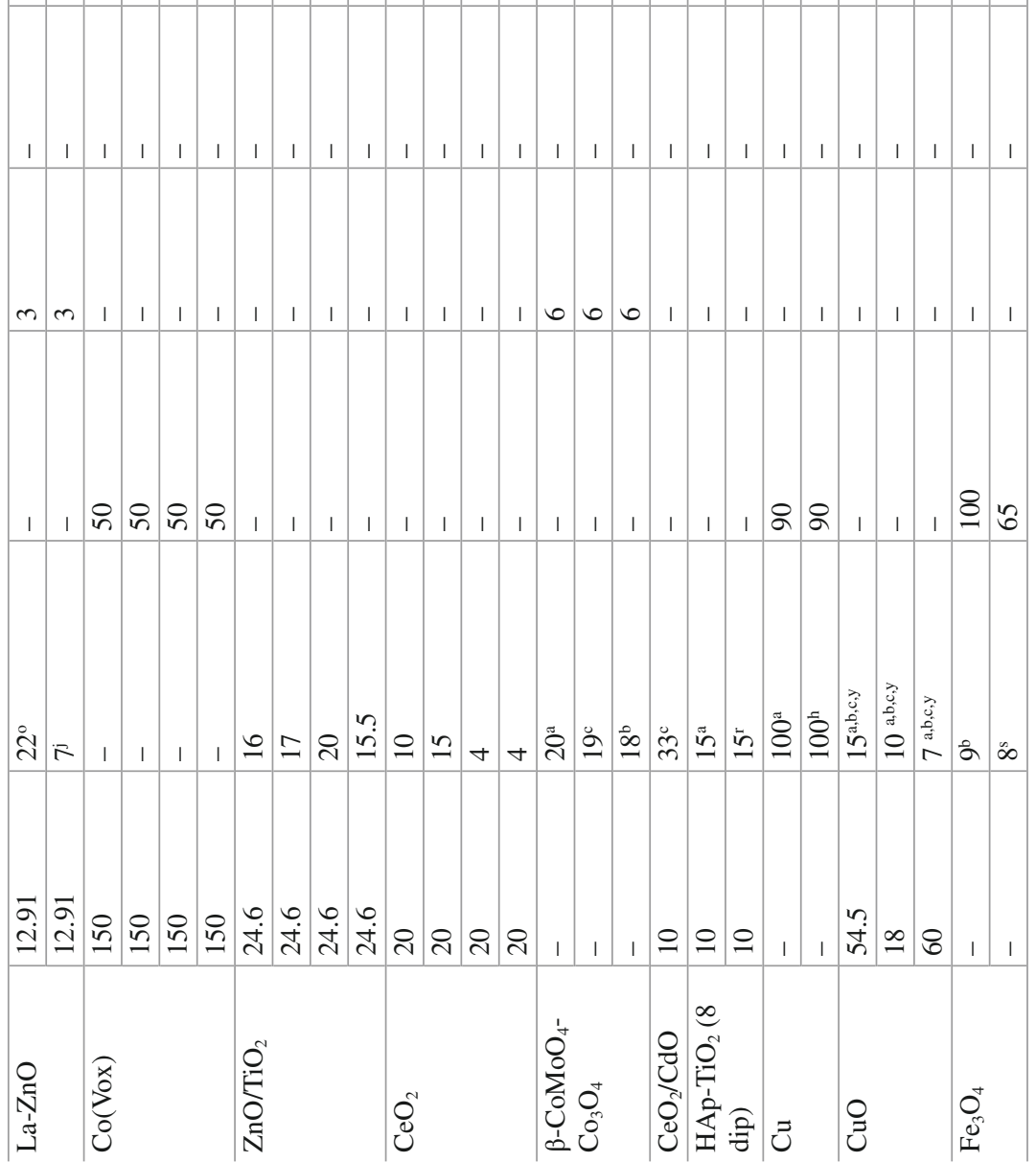




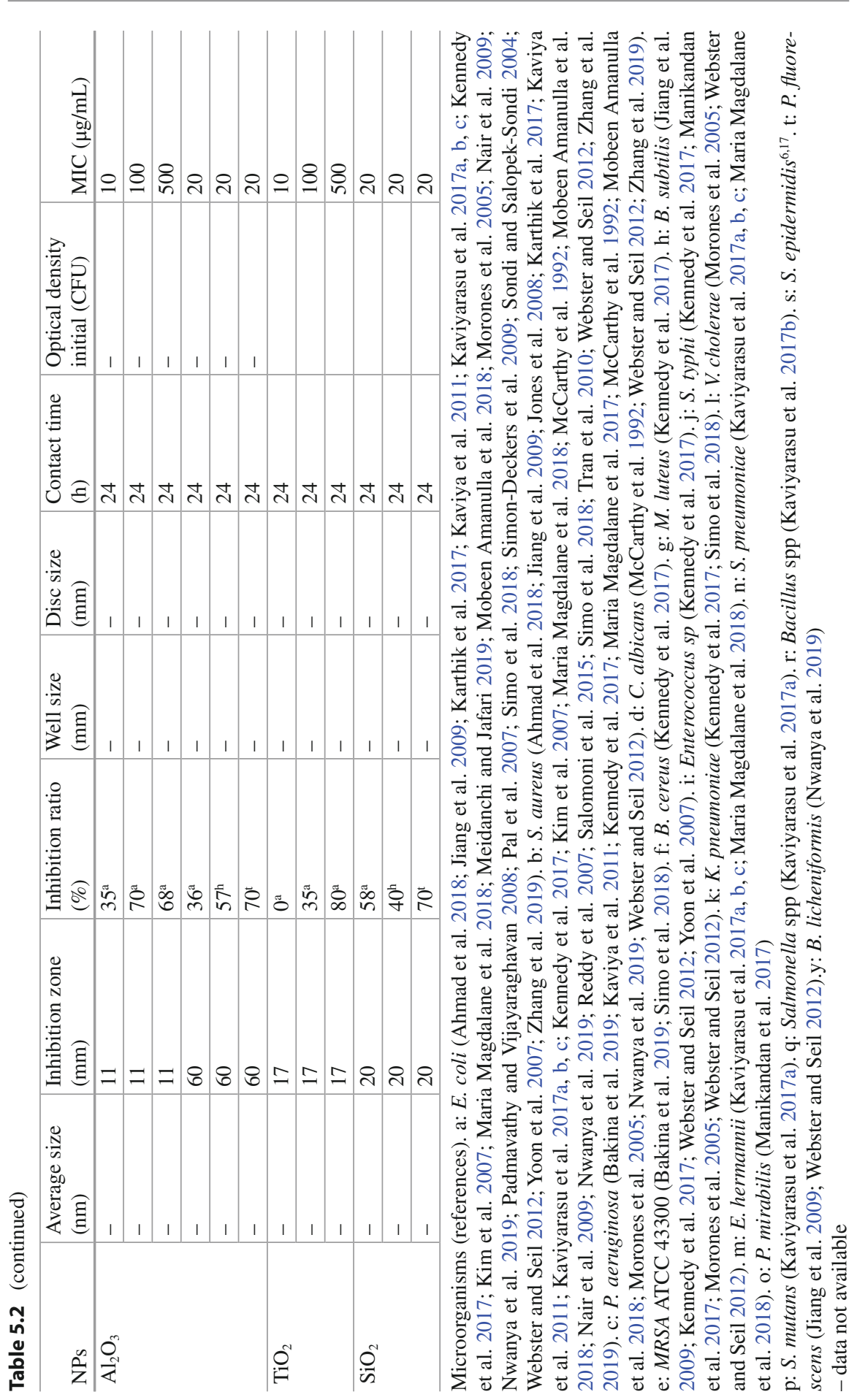


active $\left(\mathrm{m}^{2} \mathrm{~g}^{-1}\right)$, average size $(\mathrm{nm})$, maximum inhibition zone size $(\mathrm{mm})$, inhibition Ratio (\%), initial (O.D. initial) and final (O.D. final) microorganism optical density, well and disk diffusion size $(\mathrm{mm})$, contact time $(\mathrm{h})$, nanoparticle concentration $(\mu \mathrm{g} /$ $\mathrm{mL}$ ) and the microorganism species, were considered for the multi-criteria analyses. Statistical methods such as the MCA and PCA were used for the 123 observations to follow the association and the variation of qualitative and quantitative data, respectively. These parameters were chosen based on the considered criteria for testing the effectiveness of nanomaterials to inhibit microbial growth.

\subsubsection{Multiple Correspondence Analysis (MCA)}

MCA is a statistical approach to study the association and affinity, between categorical data (Dungey et al. 2018). This method uses a binary code matrix (0 or 1 ) to evaluate the standard correspondence between the rows and columns of the categorical data (Van Stan et al. 2016). The association between the qualitative variables, which are formed by the nanoparticles and the gram stain type of the microorganism species, was studied by choosing the MCA. A map was drawn to visualise the distances between these categories of the qualitative variables in to two dimensions with $F 1$ and $F 2$ axis for $X$ and $Y$ axis, respectively. The association between the qualitative variables was appreciated by their affinity to the axis F1 and F2 and by their distance from the axis origin. MCA considers the $\left(d_{I}^{2}(i, 0)\right)$ squared distance of the $i$ th row profile from the axis origin $O$, which is the $i$ th row profile Euclidean distance (Eq. 5.1) (Costa et al. 2013):

$$
d_{I}^{2}(i, 0)=\sum_{m=1}^{M *} f_{i m}^{2}
$$

Where, $M$ is the dimension correspondence plot; when the distance of the $i$ th row profile is great, the profile of the category $i$ would deviate the column and row categories average profile. Variables that have a same direction from the origin are highly associated (Dungey et al. 2018). $f_{i m}^{2}$ is the $(i, m)$ th element of $F . F$ is the derivation of the coordinates of row profile for singular ordered correspondence analysis using $\mathrm{BMD}^{26}$. Table 5.1 enlists qualitative input data for MCA.

\subsubsection{Principal Component Analysis (PCA)}

PCA is a statistical approach to study the correlation and the variance between continuous variables (Ayele et al. 2015). PCA was used to study the variance between the quantitative variables such as the nanoparticle size, the inhibition zone size, eliminated microorganisms' characteristics, the well size, the disc size, the contact time, the microorganism initial density and the initial concentration of the nanoparticles. The PCA method uses an orthogonalisation technique than a distance measure which is used in the MCA (Dungey et al. 2018). Two hypotheses, which are the null $\left(\mathrm{H}_{0}\right)$ and alternative hypothesis $\left(\mathrm{H}_{\mathrm{a}}\right)$, were considered in the PCA. $\mathrm{H}_{0}$ defines 
the absence of significant correlation between the variables. $\mathrm{H}_{\mathrm{a}}$ states that at least there are some correlations between the studied variables. Bartlett's sphericity test was run to evaluate the validity of each hypotheses. A Pearson $(n)$ matrix was chosen to show the correlation between these quantitative variables. A Pearson ratio $\alpha_{i j}$ for each $(i, j)$ th cell entry as described by Goodman (1985) was used to measure the departure from row $i$ and column $j$ independence, according to Eq. 5.2:

$$
\alpha_{i j}=\frac{p_{i j}}{p_{i,}, p_{. j}}
$$

The $(i, j)$ th matrix $\Delta$ cell value is the Pearson ration $\alpha_{i j}$. $\Delta$ is defined by Eq. 5.3:

$$
\Delta=D_{I}^{-1} P D_{J}^{-1}
$$

Where, $D_{I}$ : is the $I \times I$ diagonal of $\Delta$ with $(i, i)$ th cell entry named $p_{i}$; and $D_{J}$ is the $J \times J$ diagonal of $\Delta$ with $(j, j)$ th cell entry named $p_{. j}$.

If $\Delta=I \times J=1, J$ columns and $I$ rows are independent. A Pearson ratio value with is significantly different from 1 defines the dependence between $I$ rows and $J$ columns. Table 5.2 enlists quantitative input data for PCA.

Software XLSTAT v.15.1 was used to treat the data for PCA and MCA with 95\% as confidence interval.

\subsection{Results and Discussion}

\subsubsection{Microorganism Affinity with Nanoparticles}

MCA showed the affinity between the microorganisms and the nanoparticles, indicating a variables matrix coefficient belonging to each $F 1$ and $F 2$ axis as shown in Table 5.3. Bold values are significant at the level $\alpha=0.05$. $F 1$ axis has significant values, which regroups bacteria, which are gram negative and gram positive with nanoparticles $\mathrm{Ag}, \mathrm{La}-\mathrm{ZnO}$ and $\mathrm{SiO}_{2}$. However, bacteria which are gram negative were determined to be deactivated by La-ZnO NPs. A similar trend was observed for gram positive bacteria and $\mathrm{Ag}$-including $\mathrm{SiO}_{2}$-NPs. Axis $F 2$ was defined by the following significant parameters: fungi, gram positive bacteria, Ag-and $\mathrm{ZnO}-\mathrm{NPs}$. Nevertheless, a similar trend was observed for fungi and AgNPs including for gram positive bacteria and the ZnO-NPs. A correlation was deemed feasible for the parameters which have a similar trend (Costa et al. 2013).

Figure 5.1 presents the MCA plot for the qualitative variable for MCA. A majority of the variables belonging to the $F 1$ axis explained $80.86 \%$ of the data and only $19.14 \%$ of the data were explained by the $F 2$ axis. The data spread was homogenous around the axis centre. Only fungi were far from the axis centre, which meant that this parameter behaved differently to the mean of the observable data (Dungey et al. 2018). However, fungi and Ag-NPs had a similar trend, which formed the first group (encircled with large dash line pink colour). In fact, Fig. 5.1 confirmed the affinities between the microorganisms and the nanoparticles by regrouping the parameters which have the same trend (Ayele et al. 2015). Three groups were observed in Fig. 5.1. The first 
Table 5.3 Variables matrix coefficient for multiple correspondence analysis (MCA) of each qualitative parameter

\begin{tabular}{|c|c|c|}
\hline Qualitative variables & $F 1$ & $F 2$ \\
\hline Fungi & 1.5427 & -5.3448 \\
\hline $\begin{array}{l}\text { Gram } \\
\text { bacteria-negative }\end{array}$ & -5.9618 & -0.5980 \\
\hline Gram bacteria-positive & 5.5575 & 2.0782 \\
\hline NPs-Ag & 2.8783 & -4.8522 \\
\hline $\begin{array}{l}\text { NPs-AgNPs } \\
\text { nanocellulose }\end{array}$ & -1.8836 & -0.3883 \\
\hline NPs-CeO ${ }_{2}$ & 0.2536 & 1.2868 \\
\hline $\mathrm{NPs}-\mathrm{CeO}_{2} / \mathrm{CdO}$ & -1.8836 & -0.3883 \\
\hline NPs-Co (Vox) & -1.8148 & 0.2431 \\
\hline NPs-Cu28-Fe72 & -0.9646 & 0.5066 \\
\hline NPs-HAp- $\mathrm{TiO}_{2}(8 \mathrm{dip})$ & 0.1757 & 0.8915 \\
\hline NPs-La-ZnO & -2.6903 & -0.5546 \\
\hline $\mathrm{NPs}-\mathrm{SiO}_{2}$ & 2.1296 & 1.6367 \\
\hline $\mathrm{NPs}-\mathrm{Ta}_{2} \mathrm{O}_{5}$ & -1.8836 & -0.3883 \\
\hline NPs-ZnO & 1.7893 & 3.1015 \\
\hline $\mathrm{NPs}-\mathrm{ZnO} / \mathrm{TiO}_{2}$ & -0.9646 & 0.5066 \\
\hline $\mathrm{NPs}-\beta-\mathrm{CoMoO}{ }_{4}-\mathrm{Co}_{3} \mathrm{O}_{4}$ & -0.9646 & 0.5066 \\
\hline
\end{tabular}

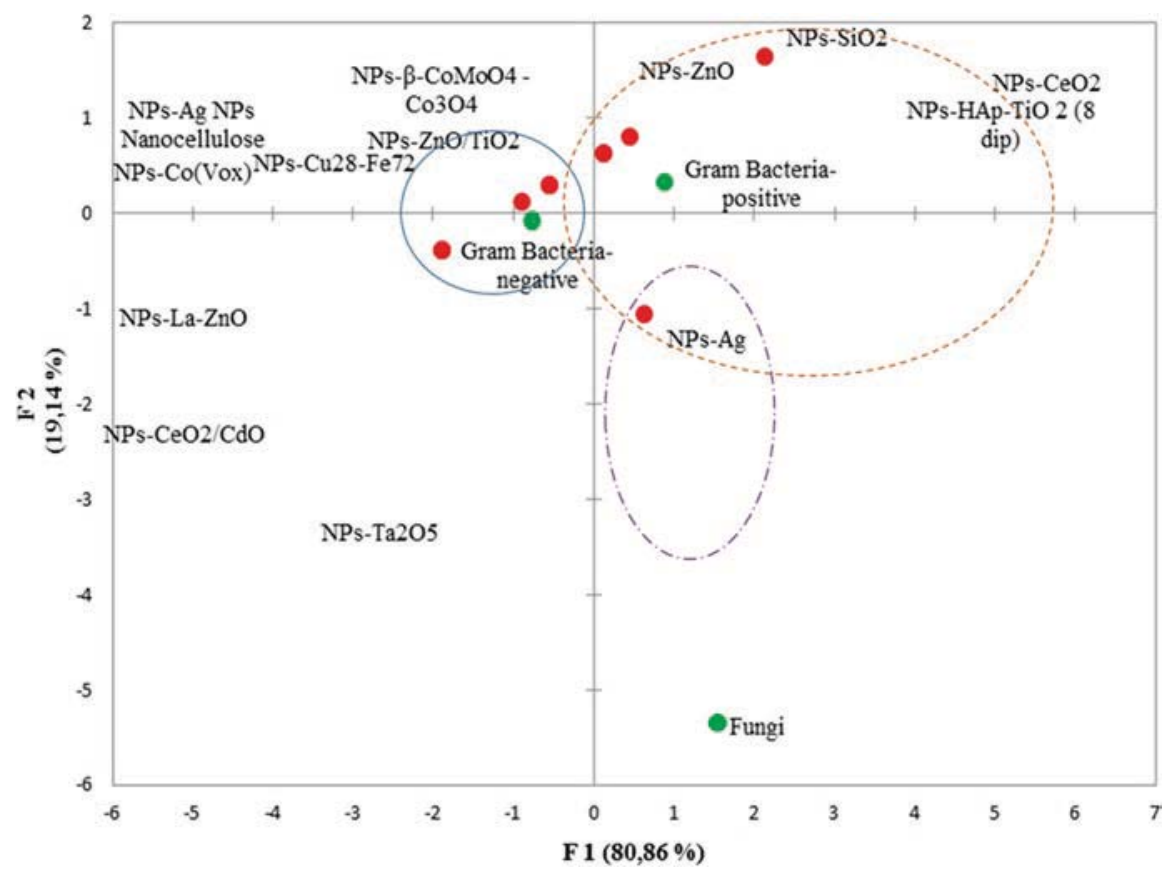

Fig. 5.1 Principal multiple correspondence analysis (MCA) plot for the variable qualitative of the nanoparticle's antimicrobial activities 
group was previously described, which showed a regrouping between the fungi and the NPs Ag. The second group is encircled in orange colour (short dash line), which regroups the gram positive bacteria with the following NPs: $\mathrm{Ag}, \mathrm{SiO}_{2}, \mathrm{ZnO}, \mathrm{CeO}_{2}$ and $\mathrm{TiO}_{2}$. The last group, encircled by a blue colour (continuous line), is formed by the gram negative bacteria with NPs: $\mathrm{La}-\mathrm{ZnO}, \mathrm{CeO}_{2} \mathrm{CdO}, \mathrm{TaO}_{5}, \mathrm{Co}$ (Vox), $\mathrm{Cu}, \mathrm{CuO}$, $\mathrm{TiO}_{2}$. Each type of microorganism was directly linked with several associated NPs, but only the matrix coefficient of each qualitative variable in Table 5.3, confirms the NPs highly correlated with specific microorganism. NPs that have bold values have significant antimicrobial properties towards gram positive bacteria, which are the NPs: $\mathrm{Ag}, \mathrm{SiO}_{2}$ and $\mathrm{ZnO}$ with NPs of $\mathrm{La}-\mathrm{ZnO}$ having an affinity for gram negative bacteria with only the Ag-NPs having antimicrobial activity against Fungi.

\subsubsection{Antimicrobial Test Conditions}

The scree plot of the PCA displayed as a 2-dimensional (2D) depiction for the comparative location of the quantitative variables to each other is presented in Fig. 5.2. Data variability was computed in eight dimensions as illustrated by the axis from $F 1$ to $F 8$ in comparison for the cumulative variability and the Eigen values as shown in Fig. 5.2. Based on the scree plot, PCA revealed that the treated data was reliable in a $2 \mathrm{D}$ spacing when comparing $F 1$ against $F 2=45.50 \%$.

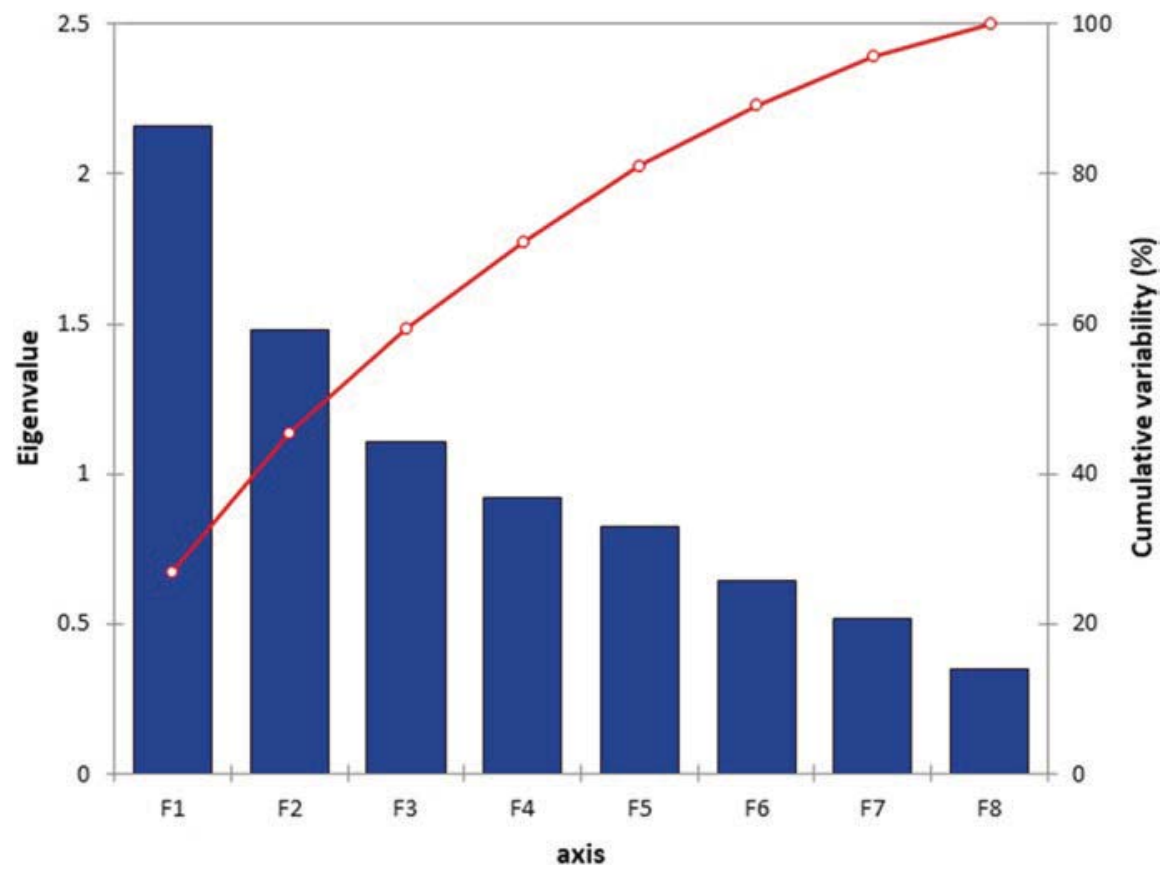

Fig. 5.2 Principal component analysis (PCA) scree plot depicting the variability of the quantitative data in the eight dimensions against the cumulative variability comparative to the eigenvalues 
The Pearson correlation matrix table (Table 5.4) shows the correlation coefficient between each considered parameter to NPs test conditions. The inhibition zone size was demonstrably correlated to the MIC, the well size and the disc size with correlation coefficient $\left(r^{2}\right)$ of $0.9598,0.9399$ and 0.9482 , respectively. Besides, the well size was positively correlated to disc sizes $\left(r^{2}=0.9787, \alpha=0.05\right)$ and to MIC $\left(r^{2}=0.2783, \alpha=0.05\right)$. The disc size as well was shown to have a positive correlation with the MIC with a correlation coefficient $\left(r^{2}\right)$ of 0.4814 and $\alpha$ of 0.05 . The values of the correlation coefficient have a confidence interval of $95 \%$ which agrees with the hypothesis alternative (Ha), which states that at least one of the correlations between the variables is significantly different from 0 .

Correlation of the PCA is displayed in Fig. 5.3, which depicts the projection of the NPs antimicrobial activities and quantitative variables in the $2 \mathrm{D}$ space. A positive correlation was observed between the IZ of the microorganism growth and the MIC of the NPs. Besides, the PCA revealed a positive correlation between the well size and disc diffusion size created on the agar plates during the NPs antimicrobial activity tests. A negative correlation was observed between the average size of the NPs and the contact time with the test microorganisms. These correlations were similar to the correlation matrix of Pearson (Table 5.4). The IZ size is defined by not only the MIC but also the well and disc size containing the NPs on the agar plates. Therefore, the necessity to vary the NPs concentration to improve the antimicrobial test was retained as reported in Webster and Seil (2012). Effectively, when the MIC is high, the IZ size would be large as reported in Simon-Deckers et al. (2009). Besides, the NPs average size plays a major role on the contact time with the microorganism.

Table 5.4 Correlation matrix (Pearson $(n)$ ) of quantitative variables for nanoparticles' antimicrobial activity

\begin{tabular}{|c|c|c|c|c|c|c|c|c|}
\hline Variables & $\begin{array}{l}\text { Average } \\
\text { size } \\
(\mathrm{nm})\end{array}$ & $\begin{array}{l}\mathrm{IZ} \\
(\mathrm{mm})\end{array}$ & $\begin{array}{l}\text { Ratio } \\
(\%)\end{array}$ & \begin{tabular}{|l} 
Well \\
size \\
$(\mathrm{mm})$ \\
\end{tabular} & \begin{tabular}{|l|} 
Disc \\
size \\
$(\mathrm{mm})$ \\
\end{tabular} & $\begin{array}{l}\text { Contact } \\
\text { time (h) }\end{array}$ & $\begin{array}{l}\text { OD } \\
\text { (initial) }\end{array}$ & $\begin{array}{l}\text { MIC } \\
(\mu \mathrm{g} / \mathrm{mL})\end{array}$ \\
\hline $\begin{array}{l}\text { Average } \\
\text { Size } \\
(\mathrm{nm})\end{array}$ & 1 & 0.0321 & -0.1438 & -0.0641 & 0.0200 & -0.9893 & -0.1410 & -0.1448 \\
\hline $\mathrm{IZ}(\mathrm{mm})$ & 0.0321 & 1 & 0.0000 & 0.9399 & 0.9482 & 0.1550 & 0.0232 & 0.9598 \\
\hline $\begin{array}{l}\text { Ratio } \\
(\%)\end{array}$ & -0.1438 & 0.0000 & 1 & 0.0000 & -0.0032 & -0.1267 & 0.0321 & -0.0039 \\
\hline $\begin{array}{l}\text { Well } \\
\text { size } \\
(\mathrm{mm})\end{array}$ & -0.0641 & 0.9399 & 0.0000 & 1 & 0.9787 & 0.0000 & 0.0000 & 0.2783 \\
\hline $\begin{array}{l}\text { Disc } \\
\text { size } \\
(\mathrm{mm})\end{array}$ & 0.0200 & 0.9482 & -0.0032 & 0.9787 & 1 & 0.0116 & -0.0497 & 0.4814 \\
\hline $\begin{array}{l}\text { Contact } \\
\text { time (h) }\end{array}$ & -0.9893 & 0.1550 & -0.1267 & 0.0000 & 0.0116 & 1 & 0.2706 & 0.2034 \\
\hline $\begin{array}{l}\text { OD } \\
\text { (initial) }\end{array}$ & -0.1410 & 0.0232 & 0.0321 & 0.0000 & -0.0497 & 0.2706 & 1 & -0.0725 \\
\hline $\begin{array}{l}\text { MIC } \\
(\mu \mathrm{g} / \mathrm{mL})\end{array}$ & -0.1448 & 0.9598 & -0.0039 & 0.2783 & 0.4814 & 0.2034 & -0.0725 & 1 \\
\hline
\end{tabular}




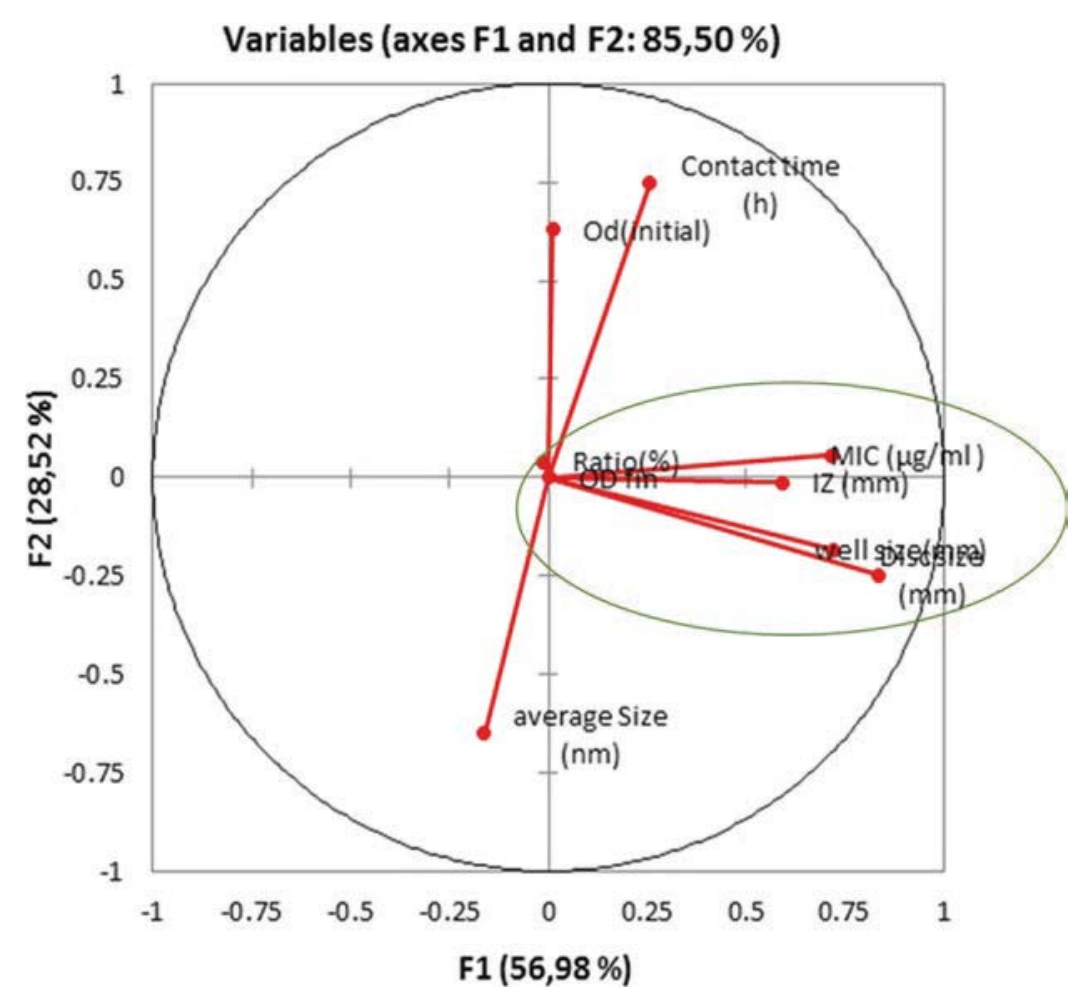

Fig. 5.3 Principal component analysis (PCA) correlation circle depicting the projection of the quantitative variables for nanoparticles antimicrobial activities

Similarly, when the NPs average size is large, the contact time is reduced. The NPs with a large average size effectively inhibited a few microorganisms growth.

\subsection{Conclusion}

MCA and PCA were investigated to study the correlation between the qualitative and quantitative variables, respectively, on the antimicrobial activity effectiveness of numerous NPs. Qualitative variables through the MCA showed the affinity between the gram positive bacteria and $\mathrm{Ag}-, \mathrm{SiO}_{2}$ - and $\mathrm{ZnO}-\mathrm{NPs}$, while for the gram negative bacteria it was the NPs of ZnO. For the Fungi, this was observed in AgNPs. The PCA further highlighted a positive correlation of the inhibition zone (IZ) size with the well size, disc size and the minimum inhibitory concentration (MIC) with $r^{2}>0.90, \alpha=0.05$. A negative correlation was observed between the NPs average size and the contact time. Therefore, the choice of NP types for antimicrobial activity effectiveness depends on the microorganism type and the MIC, with some influence being associated to the well size and the disc size. It is necessary to vary the concentration of the NPs to improve the effectiveness of NP against pathogens. 
Also, research on the NPs antimicrobial application on fungi should be investigated in future studies to ascertain the effectiveness of other NPs for antifungal efficacy.

Acknowledgement We are grateful to the National Research Foundation (NRF) and the World Academy of Sciences (TWAS) for their financial support under grant unique number 110793 and the UNESCO-UNISA Africa Chair in Nanosci ences/Nanotechnology Laboratories, College of Graduate Studies, University of South Africa (UNISA), Muckleneuk Ridge, Pretoria, South Africa as host institution.

\section{References}

Ahmad NAY, Zain NM, Pauzi N (2018) Synthesis of ZnO nanoparticles with chitosan as stabilizing agent and their antibacterial properties against Gram-positive and Gram-negative bacteria. Int J Biol Macromol 124:1132-1136. https://doi.org/10.1016/j.ijbiomac.2018.11.228

Ayele D, Zewotir T, Mwambi H (2015) Multiple correspondence analysis as a tool for analysis of large health surveys in African settings. Afr Health Sci 14:1036-1045. https://doi.org/10.4314/ ahs.v14i4.35

Bakina OV, Glazkova EA, Svarovskaya NV et al (2019) Janus-like Cu-Fe bimetallic nanoparticles with high antibacterial activity. Mater Lett 242:187-190. https://doi.org/10.1016/j. matlet.2019.01.105

Beh EJ (2008) Simple correspondence analysis of nominal-ordinal contingency tables. J Appl Math Decis Sci 2008:1-17. https://doi.org/10.1155/2008/218140

Costa PS, Santos NC, Cunha P et al (2013) The use of multiple correspondence analysis to explore associations between categories of qualitative variables in healthy ageing. J Aging Res 2013:1-12. https://doi.org/10.1155/2013/302163

Diallo A, Manikandan E, Rajendran V, Maaza M (2016) Physical \& enhanced photocatalytic properties of green synthesized $\mathrm{SnO} 2$ nanoparticles via Aspalathus linearis. J Alloys Compd 681:561-570. https://doi.org/10.1016/j.jallcom.2016.04.200

Dungey M, Doko Tchatoka F, Yanotti MB (2018) Using multiple correspondence analysis for finance: a tool for assessing financial inclusion. Int Rev Financ Anal 59:212-222. https://doi. org/10.1016/j.irfa.2018.08.007

Goodman LA (1985) The analysis of cross-classified data having ordered and/or unordered categories: associationmodels, correlationmodels, and asymmetry models for contingency tables with or without missing entries. Ann Stat 13:10-69

Jiang W, Mashayekhi H, Xing B (2009) Bacterial toxicity comparison between nano- and micro-scaled oxide particles. Environ Pollut 157:1619-1625. https://doi.org/10.1016/j. envpol.2008.12.025

Jones N, Ray B, Ranjit KT, Manna AC (2008) Antibacterial activity of ZnO nanoparticle suspensions on a broad spectrum of microorganisms. FEMS Microbiol Lett 279:71-76. https://doi. org/10.1111/j.1574-6968.2007.01012.x

Karthik S, Siva P, Balu KS et al (2017) Acalypha indica-mediated green synthesis of $\mathrm{ZnO}$ nanostructures under differential thermal treatment: effect on textile coating, hydrophobicity, UV resistance, and antibacterial activity. Adv Powder Technol 28:3184-3194. https://doi. org/10.1016/j.apt.2017.09.033

Kaviya S, Santhanalakshmi J, Viswanathan B et al (2011) Biosynthesis of silver nanoparticles using citrus sinensis peel extract and its antibacterial activity. Spectrochim Acta A Mol Biomol Spectrosc 79:594-598. https://doi.org/10.1016/j.saa.2011.03.040

Kaviyarasu K, Geetha N, Kanimozhi K et al (2017a) In vitro cytotoxicity effect and antibacterial performance of human lung epithelial cells A549 activity of zinc oxide doped $\mathrm{TiO}_{2}$ nanocrystals: Investigation of bio-medical application by chemical method. Mater Sci Eng C 74:325-333. https://doi.org/10.1016/j.msec.2016.12.024 
Kaviyarasu K, Maria Magdalane C, Kanimozhi K et al (2017b) Elucidation of photocatalysis, photoluminescence and antibacterial studies of $\mathrm{ZnO}$ thin films by spin coating method. $\mathrm{J}$ Photochem Photobiol B Biol 173:466-475. https://doi.org/10.1016/j.jphotobiol.2017.06.026

Kaviyarasu K, Mariappan A, Neyvasagam K et al (2017c) Photocatalytic performance and antimicrobial activities of HAp-TiO 2 nanocomposite thin films by sol-gel method. Surf Interface 6:247-255. https://doi.org/10.1016/j.surfin.2016.10.002

Kennedy J, Ramalingam RJ, Al Lohedan HA, Ali MV, Maaza M (2017) Bioreduction potentials of dried root of Zingiber officinale for a simple green synthesis of silver nanoparticles: antibacterial studies. J Photochem Photobiol B Biol 177:62-68. https://doi.org/10.1016/j.jphotobiol.2017.10.007

Kim JS, Kuk E, Yu KN et al (2007) Antimicrobial effects of silver nanoparticles. Nanomed Nanotechnol Biol Med 3:95-101. https://doi.org/10.1016/j.nano.2006.12.001

Makvana S, Krilov LR (2015) Escherichia coli infections. Pediatr Rev 36:167-171. https://doi. org/10.1542/pir.36-4-167

Manikandan A, Manikandan E, Meenatchi B et al (2017) Rare earth element (REE) lanthanum doped zinc oxide ( $\mathrm{La}: \mathrm{ZnO}$ ) nanomaterials: synthesis structural optical and antibacterial studies. J Alloys Compd 723:1155-1161. https://doi.org/10.1016/j.jallcom.2017.06.336

Mao C, Song Y, Chen L et al (2019) Human health risks of heavy metals in paddy rice based on transfer characteristics of heavy metals from soil to rice. Catena 175:339-348. https://doi. org/10.1016/j.catena.2018.12.029

Maria Magdalane C, Kaviyarasu K, Judith Vijaya J et al (2017) Photocatalytic degradation effect of malachite green and catalytic hydrogenation by UV-illuminated $\mathrm{CeO} 2 / \mathrm{CdO}$ multilayered nanoplatelet arrays: Investigation of antifungal and antimicrobial activities. J Photochem Photobiol B Biol 169:110-123. https://doi.org/10.1016/j.jphotobiol.2017.03.008

Maria Magdalane C, Kaviyarasu K, Raja A et al (2018) Photocatalytic decomposition effect of erbium doped cerium oxide nanostructures driven by visible light irradiation: Investigation of cytotoxicity, antibacterial growth inhibition using catalyst. J Photochem Photobiol B Biol 185:275-282. https://doi.org/10.1016/j.jphotobiol.2018.06.011

Mbu E, Dodoo Arhin D, Ntwampe KOS et al (2018) Synthesis and characterization of nanostructured cupric oxide for photo-catalytic applications. In: ASETH-18, ACABES-18 \& EBHSSS-18 19-20 November 2018. Eminent Association of Pioneers, Cape Town

McCarthy TJ, Zeelie JJ, Krause DJ (1992) The antimicrobial action of zinc ion/antioxidant combinations. J Clin Pharm Ther 17:51-54. https://doi.org/10.1111/j.1365-2710.1992.tb01265.x

Meidanchi A, Jafari A (2019) Synthesis and characterization of high purity Ta2O5 nanoparticles by laser ablation and its antibacterial properties. Opt Laser Technol 111:89-94. https://doi. org/10.1016/j.optlastec.2018.09.039

Mekuto L, Kim YM, Ntwampe SKO et al (2018) Heterotrophic nitrification-aerobic denitrification potential of cyanide and thiocyanate degrading microbial communities under cyanogenic conditions. Environ Eng Res 24:254-262. https://doi.org/10.4491/eer.2018.147

Mobeen Amanulla A, Jasmine Shahina S, Sundaram R et al (2018) Antibacterial, magnetic, optical and humidity sensor studies of $\beta-\mathrm{CoMoO} 4-\mathrm{Co} 3 \mathrm{O} 4$ nanocomposites and its synthesis and characterization. J Photochem Photobiol B Biol 183:233-241. https://doi.org/10.1016/j. jphotobiol.2018.04.034

Morones JR, Elechiguerra JL, Camacho A et al (2005) The bactericidal effect of silver nanoparticles. Nanotechnology 16:2346-2353. https://doi.org/10.1088/0957-4484/16/10/059

Nair S, Sasidharan A, Divya Rani VV et al (2009) Role of size scale of ZnO nanoparticles and microparticles on toxicity toward bacteria and osteoblast cancer cells. J Mater Sci Mater Med 20:235-241. https://doi.org/10.1007/s10856-008-3548-5

Nwanya AC, Razanamahandry LC, Bashir AKH et al (2019) Industrial textile effluent treatment and antibacterial effectiveness of Zea mays L. Dry husk mediated bio-synthesized copper oxide nanoparticles. J Hazard Mater 375:281-289. https://doi.org/10.1016/j.jhazmat.2019.05.004

Padmavathy N, Vijayaraghavan R (2008) Enhanced bioactivity of $\mathrm{ZnO}$ nanoparticles—an antimicrobial study. Sci Technol Adv Mater 9:035004. https://doi.org/10.1088/1468-6996/9/3/035004

Pal S, Tak YK, Song JM (2007) Does the antibacterial activity of silver nanoparticles depend on the shape of the nanoparticle? A study of the Gram-negative bacterium Escherichia coli. Appl Environ Microbiol 73:1712-1720. https://doi.org/10.1128/AEM.02218-06 
Razanamahandry LC, Andrianisa HA, Karoui H et al (2016) Biodegradation of free cyanide by bacterial species isolated from cyanide-contaminated artisanal gold mining catchment area in Burkina Faso. Chemosphere 157:71-78. https://doi.org/10.1016/j.chemosphere.2016.05.020

Razanamahandry LC, Karoui H, Andrianisa HA, Yacouba H (2017) Bioremediation of soil and water polluted by cyanide: a review. African J Environ Sci Technol 11:272-291

Reddy KM, Feris K, Bell J et al (2007) Selective toxicity of zinc oxide nanoparticles to prokaryotic and eukaryotic systems. Appl Phys Lett 90:213902. https://doi.org/10.1063/1.2742324

Salomoni R, Léo P, Rodrigues MFA (2015) Antibacterial activity of silver nanoparticles (AgNPs) in Staphylococcus aureus and cytotoxicity effect in mammalian cells. In: The battle against microbial pathogens: basic science, technological advances and educational programs. FORMATEX, Badajoz, pp 851-857

Simo A, Drah M, Sibuyi NRS et al (2018) Hydrothermal synthesis of cobalt-doped vanadium oxides: antimicrobial activity study. Ceram Int 44:7716-7722. https://doi.org/10.1016/j. ceramint.2018.01.198

Simon-Deckers A, Loo S, Mayne-L'hermite M et al (2009) Size-, composition- and shapedependent toxicological impact of metal oxide nanoparticles and carbon nanotubes toward bacteria. Environ Sci Technol 43:8423-8429. https://doi.org/10.1021/es9016975

Siripireddy B, Mandal BK (2017) Facile green synthesis of zinc oxide nanoparticles by Eucalyptus globulus and their photocatalytic and antioxidant activity. Adv Powder Technol 28:785-797. https://doi.org/10.1016/j.apt.2016.11.026

Sondi I, Salopek-Sondi B (2004) Silver nanoparticles as antimicrobial agent: a case study on E. coli as a model for Gram-negative bacteria. J Colloid Interface Sci 275:177-182. https://doi. org/10.1016/j.jcis.2004.02.012

Taylor EN, Webster TJ (2009) The use of superparamagnetic nanoparticles for prosthetic biofilm prevention. Int J Nanomedicine 4:145-152

Tong SYC, Davis JS, Eichenberger E et al (2015) Staphylococcus aureus infections: epidemiology, pathophysiology, clinical manifestations, and management. Clin Microbiol Rev 28:603-661. https://doi.org/10.1128/CMR.00134-14

Tran N, Mir A, Mallik D et al (2010) Bactericidal effect of iron oxide nanoparticles on Staphylococcus aureus. Int J Nanomedicine 5:277-283

Valgas C, de SSM, Smânia EFA, Smânia A Jr (2007) Screening methods to determine antibacterial activity of natural products. Brazil J Microbiol 38:369-380. https://doi.org/10.1590/ S1517-83822007000200034

Van Stan JT, Gay TE, Lewis ES (2016) Use of multiple correspondence analysis (MCA) to identify interactive meteorological conditions affecting relative throughfall. J Hydrol 533:452-460. https://doi.org/10.1016/j.jhydrol.2015.12.039

Wang X (2012) Nanomaterials as sorbents to remove heavy metal ions in wastewater treatment. J Environ Anal Toxicol 2:7. https://doi.org/10.4172/2161-0525.1000154

Webster TJ, Seil I (2012) Antimicrobial applications of nanotechnology: methods and literature. Int J Nanomedicine 7:2767-2781. https://doi.org/10.2147/IJN.S24805

Yacoub C, Blazquez N, Pérez-Foguet A, Miralles N (2013) Spatial and temporal trace metal distribution of a Peruvian basin: recognizing trace metal sources and assessing the potential risk. Environ Monit Assess 185:7961-7978. https://doi.org/10.1007/s10661-013-3147-x

Yoon K-Y, Hoon Byeon J, Park J-H, Hwang J (2007) Susceptibility constants of Escherichia coli and Bacillus subtilis to silver and copper nanoparticles. Sci Total Environ 373:572-575. https:// doi.org/10.1016/j.scitotenv.2006.11.007

Zhang X, Sun H, Tan S et al (2019) Hydrothermal synthesis of Ag nanoparticles on the nanocellulose and their antibacterial study. Inorg Chem Commun 100:44-50. https://doi.org/10.1016/j. inoche.2018.12.01 